\title{
Verbalization of Main Spectral Colors in Texts of Ukrainian Charms
}

\author{
S. Shuliak \\ The Chair of Applied Linguistics, \\ Pavlo Tychyna Uman State Pedagogical University, \\ Sadova, 2, 20300, Uman, Ukraine \\ O. Bezliudnyi
}

The Department of the English Language and its Methodology,

Pavlo Tychyna Uman State Pedagogical University,

Sadova, 2, 20300, Uman, Ukraine

V. Koval

The Chair of Ukrainian language with teaching methods, Pavlo Tychyna Uman State Pedagogical University, Sadova, 2, 20300, Uman, Ukraine

K. Masliuk

The Chair of Ukrainian language with teaching methods, Pavlo Tychyna Uman State Pedagogical University, Sadova, 2, 20300, Uman, Ukraine

Doi: 10.2478/jesr-2019-0023

\begin{abstract}
The purpose of this article is to study the verbalization of the main spectral colors in the texts of Ukrainian charms. In order to achieve the goal, the following tasks must be realized: 1- To determine the emotional and estimated semantics of red, blue, green, yellow colors and the function performed by the above-mentioned color titles to ensure pragmatics of charms. 2- To find out the direct and associative values of the main spectral colors in the texts of Ukrainian charms. 3- To discover the most common morphological category of color titles. It is established that the titles of the main spectral colors in the charming texts are usually filled with positive emotional-estimated semantics, but sometimes they are able to acquire other semantic shades of contradictory significance. As a result, the adjective is defined as the most common morphological category of color titles. The direct and associative values of the main spectral colors in the texts of Ukrainian charms are found. In conclusion, the color epithets of red, blue, green, yellow are capable of performing an emotional and expressive function, which contribute to the pragmatic effect of charms.
\end{abstract}

Keywords: Colors, Titles, Charms, Text, Verbalization

\section{Introduction}

\subsection{Research Methods}

\subsubsection{Analysis Result}

The folklore language occupies a special place among the varieties of artistic language, keeping in the text's traces of archaic ideological concept, cults and rituals (Toporov, 1998). For the ancient 
Slavs-pagans, the magic of the word was inseparable not only from the magic of action, but also from the subject's magic. Charms are also considered as a ritual, in which both text and ritual acts, and circumstances of execution are important (Petrov, 1981). In linguistics literature, there is the problem of unification of linguistic terms, so the following notation is used: color title, color name, color definition, color term, color ordering, and color adjective, color epithet. The semantic structure of color names is usually complicated by other content. The sources of the occurrence of color names are polysemy (use of names of objects, objects of nature with a certain color for the formation of new color names); lexical-morphological means (complex words, special words for the transmission of shades); loan. Cognition of linguistic forms of color studies occurs in the concepts of general linguistic theory, when the verbalization of color is explained by the peculiarities of intellectual activity of man. Color is one of the representations of the sensory experience of personality / society, which is in complex interdependencies of stability / changeability, centering / peripherality of reflection on the world. It is logical to consider the fact that color names draw attention of linguists in the field of cognitive semantics.

According to Kovalskaya, the semantic structure of color names in various functions is altered from the absolute domination of denotative meaning to its extinction and the transition to the forefront of connotative components. Therefore, it is not surprising that color becomes a marker of a positive or negative assessment of a person, phenomenon or event. Lexical-thematic paradigm is color spectrometry spectrally rich. It includes both tokens on the designation of their own colors, as well as figurative-stylistic units, indicating the associative color sign. Lexical-semantic field of colors consists of a nucleus (the primary layer of vocabulary is a direct nomination, correlated with chromatic and achromatic spectra) and periphery - secondary nominations and isioms. As Frumkin notes successfully, the study of psycholinguistics is the basis for revealing semantic relations between word-names of color. Ordinary carriers of language easily establish the identity between meanings of color names, this is the only kind of information that can be used by a researcher who does not want to engage in his own interpretation and linguistic reflection to describe the naive picture of the world of color.

Orders are a genre of verbal folklore, regular expressions, and recitative, mostly versified tyrants accompanying magical actions, movements of their performers - the healers, witches or witchers, magicians, diviners, whispers etc., and express their desire to influence the nature, the person and her relationship with the environment in the right direction (good or evil). Initially, the basis of the charm was ritual, magical actions, imitation movements, perhaps without words (Grom'iak et al., 2007). Later, verbal accompaniment becomes the main one, gaining an independent value. Charms are composed mainly on the principle of association of the idea (concept) of parallel rows: the cause and effect, the object and its image (name, image, person and its name or some kind of thing). The charms reflect the pagan worldview, they often have celestial bodies, natural elements, fantastic terrain, objects, creatures, etc., but in the era of Christianity, "in the consensual formulas included a lot of literary Christian and apocryphal elements, whole parts of Christian and heretical prayers and supplications, without whose current speeches are rarely done" (Kolessa, 1929: 10). The study of color titles is closely linked to the perception of the person of the surrounding world. Color signs give the language a variety of connotative properties and carry an extraordinary emotional and expressive charge, having a significant impact on the person at the psychological level.

Studies of color titles are devoted to the works of Gubareva (2002), Levchenko (2007), Mironova (1984), Shulinova (2001) and other linguists. For example, works presented by Shulinova "Materials and methodical recommendations for special courses on idiostylistics" Shulinova (2001: 22), and Lyric poetry of Lesya Ukrainka (poetization of semantics of color); Mironova "Color studies" Mironova (1984: 18); Solyar "Ukrainian charms: issues of origin and poetics" (Solyar, 2005: 16); Dmutrenko "Symbols of Ukrainian folklore" (Dmutrenko, 2011: 18); Gunchik "Ukrainian magicsacred folklore: the structure of the text and the peculiarities of functioning" Gunchik (2011: 18); Kotsur "Domestic science at the turn of the epoch: problems and prospects of development" (Kotsur, 2017: 22); Pechenuk "Color studies" (Pechenuk, 2009: 14); Lukinskyi "Psychological aspects of different colors perception by human" (Lukinskyi, 2017: 10); Krainikova "Adaptive color synthesis" Krainikova (2018: 20) and Hodanich "Educational value of color in Ukrainian children's 
folklore as an ethnosaving factor" Hodanich (2005: 15) reveal problematics direction of our research. And also show how relevant this topic is and is in demand on the world stage. Many authors reveal these problems only partially, or the obtained examples are not sufficiently deeply analyzed, therefore we believe that it is necessary to expand the research on this subject and to correlate Ukrainian folklore with the folklore of other countries.

Glinskaya traced the structural-semantic features and figurative and expressive functions of the coloring in the poems of Vyngranovsky. He noticed that in combination with the titles of abstract concepts, colorants neutralize their spectral significance, their use is subject to the emotional and expressive purpose (Glyvinska, 2004). Gubareva (2002) notes that in the modern Ukrainian language, the color titles form a quantitatively rich and qualitatively diverse lexical-semantic field; the color titles that are part of it are marked by uneven semantic content (color can be expressed explicitly or implicitly), different word-building structure and grammatical design; its dominant units are red, yellow, blue, green, white, black, gray, representing the basic color representations of man and belong to the constants of spiritual and material culture; The hierarchy of the seme in the structure of the value of the color may vary: from the predominance of the denotative component to its complete extinction and the emergence of the emotional-evaluative, symbolic components on the foreground (Gubareva, 2002). It is noteworthy that in the structure of each microfield, individual nominations may also be included in their general meanings, direct and figurative, and in contextual, metaphorical, and symbolic (Gubareva, 2002). In the study of Levchenko (2007) analyzed the specificity of symbols of color titles in phraseological systems. Color is available in the prototypes of all objects perceived by the organs of vision, which is why color attributes are attributed to abstract entities that are personified or objectified. A positive or negative evaluation created by color titles-components of idioms is based not on sensory sensations, objective or subjective, but on symbolism of color, which is formed for a long time within a certain culture. Determined prototype standards of colors and concepts, verbalized in color terms, their symbolism was investigated (Levchenko, 2007; Ajallooeian et al, 2015).

\section{Materials and Methods}

The purpose of this article is to study the verbalization of the main spectral colors in the texts of Ukrainian charms. In order to achieve the goal, the following tasks must be realized:

- To determine the emotional and estimated semantics of red, blue, green, yellow colors and the function performed by the above-mentioned color titles to ensure pragmatics of charms;

- To find out the direct and associative values of the main spectral colors in the texts of Ukrainian charms;

- To discover the most common morphological category of color titles.

The examples are presented as they are recorded in the texts of the Ukrainian folk charms. The main spectral colors are red, blue, and green, yellow.

Red - the color of blood and fire. On the one hand, it symbolizes beauty, joy and love for life, on the other - vengeance and devastation. The red color is used when ordering, has the ability to counter evil charms. In love magic, red thread, red seed of plants, red grapes, red stone, red matter, etc. are used. The best way to protect children from evil spirits is to attach something red to your child's hands. To protect from the hail used red Easter eggs. When treating from a bite of a serpent, the scarecrow covered the place where the snake bite, with a red cloth, and when charming the fear of the patient put near the hearth and covered his head with a red apron (Voitovich, 2005).

In Ukrainian charms, red first of all denotes the color of blood, such as: Wish you to get lost, to gone, wish you to be weak. Wish you cannot be strong to white body dry and red blood drink. They went with their teeth, with mouths on the swelling of the yellow bone, from the white body, from the red blood. Here you do not have commotion, do not beat your head, do not rub red blood, do not thumbs your heart, do not twist the white bones, and do not dry the white body. Young man, young man, god man, can you tell me, where can I send him? On the golden branches, there it should be and stand, born, prayer (name) do not dry and do not drink red blood. The red color title stands for 
the designation of the water area, such as: Sending over the red sea, / Over the wide field - / There will live, / Rend plates, / Rivers interrupt, / Sands to sprinkle, / Trees break, / and to this newborn, baptized (Fedir) / Do not have a deal. The red sea near the blue and black is the place where diseases are sent, for example: Send over the red sea, / over the blue sea, over the black sea, I over the wide field.

From the red stones comes the water: Oh, you Water Olena and Ground Tatyana! / Comes, you water, from the mountains, from the lowlands, / from the red stones, from the forests, / that so came the baby food / for the prayer, the baptized. More often, the semantics of red color title is filled with psychological meaning, which is provided by spilling in the text of the charming of red color, such as: Because St. Yuri drove on a red horse, a red horse, a red saddle, a red stirrup, a red sword, and took off the birth of a blessed cow, whammy. In charms against albugo, the red color title works along with the white and gray color titles, for example: Went Yuri on a white horse, white lips, white teeth, white himself, white dress, white cloth, led by three horsehairs: one white, the other gray, the third was red. The white will lick albugo, the gray tear, and the red blood. Note that each color indicates the color corresponding to its title: white - albugo, gray - tear, and red - blood.

Blue is a color that merges in the Ukrainian folk world with the symbols of the blue color; in Ukrainian iconography the apparel of The Virgin Mary often wears blue (Zhaivoronok, 2006). Blue is the color of the celestial space and the sea. It is the mystery of the knowledge of the world. Symbolizes honesty, good fame, loyalty. At the same time, it causes a feeling of cold and reminds of the shadow. The blue color also symbolizes the lightning, which is compared with the blue lights that run through the red flames of the burning fire. In Galicia, during a mourning, the heads were bound by black or blue scarves (Voitovich, 2005; Shirvani et al, 2015). In some charms, the blue sea is the space on which events unfold, such as: The Lord Savooht himself went through the blue sea, carrying a pound of stone under the arm, then he changed, casting a stone in a blue sea. Whoever makes a stone of stone from the blue sea will be baptized, born or in drinking, or in the meal, or in the feast, or in the riot, or in the bread of rye, you will be troubled. There lived a man (...) near the masters, did not want to serve the masters, but went on alien lands to err, but he came to a green grove, to the quiet Danube, he looked at the sea: on the blue sea there is an island; on that island there are three blue beds, on those there are three sons sitting in the beds; thought (...), discussed the court and let keys in the sea troubled.

The blue sea in the charming texts is often in harmony with the heavenly space, because blue is the color of the sky. Therefore, the blue sea can be a place of stay of the saints, for example: On the blue sea, on a red stone / The Mother of God stood, / All shoots and gifts spoke; / sent a splash over the blue sea (Pavlov,1998). Jesus was lying on the blue sea; / There the Savior rested (Pavlov,1998) and Christian relics: Evil eye, lesson, / That was mentioned, from the wind came, / Master's, Roman's, Moldavian, / Male, female,/ Blow on the blue sea, where monastery stands / In that monastery throne was / Jesus sits and books read/ The Mother of God came/ - Stop, my Son, read, / And we will go servant of God (name) the evil eye utter (Pavlov,1998). The blue sea is a distant space, which indicates the use of the preposition for, such as: We were over the blue sea.

On a blue sea, diseases are sent, for example: On a blue sea you are sent from birth to the age; Create a language, / How to cheat-drive out, / Send to a dry forest; / On a dry forest, on a black swamp, / On the river walk, on clean streams, / On thin vines, on a blue sea (Pavlov,1998); Are you gurry, whether you are vomiting, go to the blue sea, there will not be a grief for you; Go to the blue sea, into the deep ravines, there you will pour water, sprinkled with sand, baptized, born (...) you will not have a deed; I do not call you, all the sanctuaries of Christ, the great apostles, call, send you on the blue sea; are invited to take a walk: Come on, squeeze, into meadows, to pieces, / On the reeds, on the swamps, - / To the blue sea to walk / And to my newborn, / To the prayer, to the baptized / Give to sleep.

The chromatic blue color title in the texts of the order is most often used with the achromatic white-colored title, such as: On a blue sea there is a white stone; The holy Mother of God sat on the blue sea, on a white stone; On the blue sea, on the white stones, there broke three brothers; I am still going to the blue sea. On the blue sea there is a white stone, white ram on the stone. I took a white sheep, going, slipping into the servant of God (the name), and removing the nettle sore. In the Ukrainian folk orders, the blue sea is a place of cache of the key, which will ensure the inviolability 
of charming, will increase its influence, for example: I'll go outside the gate, look at the right shoulder, close all the enemies of the company, I will throw keys in the blue sea, and the presence of a fierce snake: On the blue sea, a fierce snake roar.

We meet orders in which the color of the eyes is blue, for example: I wash (name) from bad times, / From a good eye, from a black eye, / From gray eyes, from a blue eye, From a joyful eye, From a hated eye, / From male, from a woman's conversation ... (Pavlov, 1998). Blue we will see as the veins in charms like: ... rebuking from bones, from relics, from close shoulders, from blue buns; Rozhonko ladies! Already you have trampled the white body, broke the yellow bone, did not drink red blood, and cured the blue ones. Go for an oak, twilight, steppes, reeds and various roads! You stars-dawns. In charms, sometimes we find the blue color title, which characterizes the color of the sky, such as: Come down, moon, comforting my toothache, bring the evil pain under the blue sky. Green is a color that has gained symbolism of hope in the Ukrainian folk world, since it has long been associated with the spring and the green fields that have to be cropped; at the same time, it symbolizes youth (Zhaivoronok, 2006).

Green (muddy) - in folk culture, it is matched with vegetation, immaturity, variability, and at the same time it is the color of the spring, the beauty of nature. It symbolizes the victory over evil forces, resurrection, hope and joy, but sometimes it causes anxiety. In the memorial ceremonies, green acts as the color of that world. Green is the attribute of a stranger space where evil spirits live, where evil spirits are driven out of orders. He characterizes the characters of folk demonology: the lioness, the mermaid, and the watery. In ordering one of the signs of a fever is its color - green, like grass green (Voitovich, 2005). In the charming, the green color usually acts in the direct sense, as the color of the surrounding nature, such as: Is not there a green vine in that lake meadow! The green wind drizzles, the leaves are spreading; From the roaring head, from the blush face, from the forehead, from the neck, from the eyes, from the relics, from the back, from the chest, from the stomach, from the frozen, from the handles, from the beam, from the fingers, from the joints, from all veins, from condensation, I speak, send on yellow sands, on the steep bark, on the green shoots; Oak, oak green, / I am with you / With branches and cornice. / Cudgel green, / Let us have a look and let's go together. / On you crybaby, / Sleepless, / and give my child a dream / from all sides, / and sleeping to the white day, / to dusk, / from dusting to sowing, / from sowing to God's quest.

Yellow, yellowish - a sign that has a contradictory meaning; on the one hand, it is the color of the Sun, of gold, as if it were frozen sunlight; on the other hand, it is the color of the fallen leaves and the mature rye, which means death, that is, life in the other world; mythical beings that lead the souls to that world, have yellowish tones; one of the fevers is called jaundice; yellow circles appear on the grass where the witch moves in, or where the woman in the family is tattooed with witches; the places of the roundabouts of the mermaids are marked with a zigzag grass) (Voitovich, 2005). So, in charms - the yellow sands are the place of the unclean power: Get rid of the curse, from this sick slave to the dry forest, on the yellow sands to your king Herod! Let go of the vines, / on the waterway, / on the steep shores, / on the yellow sands; the serpent: The little son-in-law gave his fruit to the stumps, swamps, forests, on the yellow sands; and the yellow jaundice is the color of the snake, such as: As the yellow jaundice was bitten - to roar, Lord, to the tooth with macaur grains.

Yellow sands are a very distant place; for example, they send out a cloud: Boiling winds! Take this cloud on your thin wings, take it for the ocean-sea, for the warm waters, for the steep mountains, for the yellow sands, so that it will settle there, and disappeared now, forever and forever, amen; and on the yellow sand and the yellow ash send all the negatives, such as: I say to you, I choose the egg, / I witch you know, trembling hair, / I am a sword of my broom, with the legs will get you. / sending you to yellow sand, / to the yellow ash, / to let you go as water in the sea (Pavlov, 1998). Do you have a dog, whether you have a cat, or a girlfriend, or a girl, go to where the yellow sands are poured over, where the fast waters are flooded? In charming often combined three colors: St. Nikolai rides on a blue, red and white horse; there are three girls: black, blue and white; blow three winds - white, blue, red; There are three diseases - white, red, blue (Voitovich, 2005).

Find the texts of charms in which parts of the human body are represented in two colors, for example, red - yellow: You will not be here, / Here you do not walk, / Do not drink red blood, / Do 
not break the yellow bone, / And do not dry my hair; It is time for you to get sick, to make noise, to break the yellow bone, to redden the red blood; Immediately and right now, God-help, feel yourself, just like you, stand yourself in a small town, on a green landmark, where the mother gave birth, and her grandmother's ruling. Here you do not stand, do not break the yellow bone, do not suck red blood, prayed, born (by name); Do not you be here, do not break the yellow bone, do not embroider the white body, do not dry the red blood; red - blue: so that you do not swallow red blood, do not pull the blue veins, do not break the yellow bone; three colors: red - yellow - blue, such as: Evening nightly nightmare - / Here you do not stand, / Under your heart do not give up, / Do not hit your head, / Red blood does not disperse, / Yellow bones do not break, / Blue veins do not fade (Pavlov,1998); yellow - red - white: I refuse you, I call you; You do not have to come here, you do not have to luxuriate, do not break the yellow bone, do not dry red blood, do not dry the white body. Go to the boundaries of stones, the boundaries of the ravine, the boundaries of the pit - there you fight, there you have to luxuriate, rocks turn around, yellow sands to overpack, and here you will not be; red - yellow - white: Red blood shed, / Yellow bone broke, / White body worked; Here you do not walk, here you do not have to play, do not suck red blood, do not dry the yellow body, do not break the white bone; Here you do not have a place, you already walked up, got, drank the red blood, nailed the yellow body, blasted the white bone; Here you do not stand, / Do not break the yellow bone, / Do not drink red blood / From the white body, from the heart, / From the yellow bone.

Also, in the same charm text we encounter four colors: Hairy-furry! At your place, God calls you, on a new town, on a golden armchair, here you do not stand, do not break the yellow bone, do not drink red blood, do not dry the white body; Yury drove on a white horse, on a golden armchair. For him there were three pots: white, black and red. The black earth was swallowed, the red one sucked, the white albugo licked, and Saint Yuri leaped to the wolf, and from the uttering of the bucket, and the pain fell; or even six: Chickens are black, white chicken, gray chicken, red chicken, yellow chickens, clay chicken (which is the title of chickens and say so). Take the creeps of the baptized, born, prayerful baby.

\section{Results and Discussion}

The perception of the surrounding world occurs with the help of specialized sensor systems analyzers. In the process of perception there is the formation of an image of an object or phenomenon that acts on the analyzer. The units that capture perceptual feelings at the lexical level demonstrate the peculiarities of structural and semantic organization. In the process of knowing the world, man made his perceptual feelings, impressions and subjective experiences embodied in rituals, rituals, verbal formulas and images (symbols). In the article on the folklore material, we will consider the linguistic units (symbols) with the value of color and derivatives as verbal forms of complex mental processes, which include synesthetic comparisons, transform the background knowledge of the communicator (Teleutsia, 2013; Zhampeisov et al, 2018).

The importance of studying color from the standpoint of cognitive linguistics is determined by the fact that color concepts are one of the key components of the universal human conceptual picture of the world and the author's poetic picture of the world. The study of color symbolism is an actual direction of absolutely different branches of knowledge: psychology, cultural studies, linguistics, literary studies, linguistics and others, which determines the interdisciplinary nature of the object of research. The interest in linguistics is aimed at identifying the Lingui specific characteristics of the mentality through an analysis of its semantic components that occupy an important place in the collective linguistic consciousness. The text is interpreted as a complete, integral content and structural-speech product, the product of speech production, alienated from the subject of speech (speaker), in turn, is the main object of his perception and understanding. The functional orientation of the text is determined by its place and role in the processes of communication: artistic (especially poetic), educational, informational, legal, etc. The texts are mutually different in terms of integrity (content-compositional structure), connectivity (cohesia), as well as the selection of lexical and stylistic means within the corresponding genre. The perception of the text involves the allocation of structural and content supports. Any text also satisfies the requirements of continuity (relationship with the situation of communication) and contextuality 
(relationship with other texts); on the other hand, it serves as a context for certain statements that are part of it (Dolinin, 2010; Tambunan, 2018).

Usually, the need for a scientific approach to the interpretation of the text and the creation of appropriate techniques are justified by the specific properties of fiction. They say that art as a whole is a special semiotic system that is constantly changing, a special language, and that even every single piece of art text speaks to the reader in his own way; that the ideological content is embodied in a complex of all its elements, in the system of these elements (Melchakova, 2007; Pivotorak, 2004). The diversity of approaches to the interpretation of the text gives not only immense space for research, but also new difficulties in evaluating the features of the text as the material form of the work. One of them is the search for an exact criterion for interpreting a particular element of the text in the appropriate key - either as a character or as a sign, and also for interpreting the text as a system of these elements. There is an impression of an infinite number of possibilities for the interpretation of any text.

In addition to individual perception, artistic awareness, an important role in perceiving the artistic work is played by social conditions and the environment in which communicative activity takes place. An important role for the interpretation of the artistic text is the symbolic function of color markings and their correct decoding by the carriers of various linguistic cultures, in our case, the Spaniards and Ukrainians. Knowledge of color is awareness of the images of archetypes canonized by world culture. Systems of color-coding and colored characters in different languages and cultures prove the influence of the native language on the nature of the color classification (Stepanov, 1997). An analysis of color descriptors is necessary to reveal the role of color in building a visual human space and the conditionality of functioning in the language, taking into account the cultural and historical traditions of different mentality.

Representatives of the Slavic culture, to which the Ukrainians belong, are famous for their peacefulness, disobedience to aggression and violence. They are characterized by such a trait as individualism; they are mainly introverts, the highest value for which is their own family and home. All these qualities are observed in the understanding of the symbolism of color given by the peoples. Aesthetics of color grows out from the subtle perception of the Spaniards and Ukrainians of the surrounding reality. The transmission of information by color is based on emerging associations that have several layers: the common natural, later layers - the influence of the cultural traditions of the people to which the person belongs, and then the color associations of personal experiences and impressions.

\section{Conclusion}

Consequently, the titles of the main spectral colors in the charming texts are usually filled with positive emotional and evaluative semantics, but sometimes they can acquire other semantic shades of contradictory meaning, such as: yellow - the color of the sun and the color of the disease. In some texts, the blue sea is the place of the Mother of God and the Savior, while in others it is the place where diseases are sent. In orders, red, blue, yellow often represent parts of the human body: red blood, blue veins, yellow bone. In addition to the above-mentioned, the color titles used in the phrase are used in the following phrases: red sea, red stone, red horse, red saddle, red stirrups, red sword; blue sea blue eye; green vine, green cones, green bush, green squash; yellow oil, yellow sands, yellow ash, yellow jaundice, etc. The color epithets in the texts of the Ukrainian folk charms are capable of performing the emotional and expressive function, causing the corresponding emotions and creating the most favorable atmosphere for the achievement of the pragmatic effect. In adjectives, the adjective is the largest morphological category of color titles compared to nouns, verbs, and adverbs.

\section{References}

Ajallooeian, E., Gorji, Y., \& Niknejadi, F. (2015). Evaluate the Effectiveness of Social Skills Training through Group Therapy Play on Reducing Rational Aggression Boy Elementary School Student in Esfahan City. UCT Journal of Social Sciences and Humanities Research, 3(1), 1-4. 
Dmutrenko, M. 2011. Symbols of Ukrainian folklore: monograph. Kiev: UTsKD. Ukraine.

Dolinin, K. 2010. Interpretation of the text: French. Moscow: KomKniga. Russia.

Glyvinska, L. 2004. Lexical idiosystem in the poems of M. Vyngranovsky. KIEV.

Grom'iak, R., Kovaliv, Y., \& Teremka, V. 2007. Literary dictionary. Kiev: VC Academy. Ukraine.

Gubareva, G. 2002. Semantics and Stylistic Functions of the Colors in Poetic Language by Lina Kostenko. Kharkov. Ukraine.

Gunchik, I. 2011. Ukrainian magic-sacred folklore: the structure of the text and the peculiarities of functioning. L'viv: LNU named after I.Franko. Ukraine.

Hodanich, L. 2005. Educational value of color in Ukrainian children's folklore as an ethnosaving factor. She wears her osvita. No 2. Finland.

Kolessa, F. 1929. Folk songs from the Galician Lemkivshchyna. Ukraine.

Kotsur, V. 2017. Proceedings from 31st All Ukrainian scientific- practical internet conference: Domestic science at the turn of the epoch: problems and prospects of development. Pereyaslav Khmelnitsky. Ukraine.

Krainikova, T. 2018. Adaptive color synthesis. Kiev. Ukraine.

Levchenko, O. 2007. Symbols in the phraseological systems of the Ukrainian and Russian languages: linguocultural aspect. Kyiv. Ukraine.

Lukinskyi, V. 2017. Psychological aspects of different colors perception by human. Kiev. Ukraine.

Melchakova, Y. 2007. Spanish national picture of the world: the interaction of art and religion. Retrieved from http://elar.urfu.ru/bitstream/10995/1709/1/urgu0500s.pdf. Russia.

Mironova, L. 1984. Color studies. Minsk. Belarus.

Pavlov, O. 1998. Verbal magic of Ukrainians. Kiev: Biblioteka ukrayintsya. Ukraine.

Pechenuk, T. 2009. Color studies. Kiev: Grani-T. Ukraine.

Petrov, V. 1981. Charms. L'viv: Nauka. Pp. 77-142. Ukraine.

Pivotorak, L. 2004. Colorant black in phraseology as expression of lingualism (on the material of Spanish, English, Ukrainian and Russian). Culture of the peoples of the Black Sea region. No 54. Retrieved from http://dspace.nbuv.gov.ua/handle/123456789/35737. Russia.

Shirvani, M., Mohammadi, A., \& Shirvani, F. (2015). Comparative study of cultural and social factors affecting urban and rural women's Burnout in Shahrekord Township. UCT Journal of Management and Accounting Studies, 3(1), 1-4.

Shulinova, L. 2001. Materials and methodical recommendations for special courses on idiostylistics. Kyiv: VPK Kyiv University. Ukraine.

Solyar, O. 2005. Ukrainian charms: issues of origin and poetics. L'viv. Ukraine.

Stepanov, Y. 1997. Constants: Dictionary of Russian culture. Moscow: School Languages of Russian Culture. Russia.

Tambunan, H. (2018). Impact of Heuristic Strategy on Students' Mathematics Ability in High Order Thinking. International Electronic Journal of Mathematics Education, 13(3), 321-328. https://doi.org/10.12973/iejme/3928

Teleutsia, V. 2013. The characters of folklore as a means of verbalization of feelings. Ukraine.

Toporov, V. 1998. About the ritual. Introduction to the problematics. Archaic ritual in folklore and early literary monuments. Moscow. Russia.

Voitovich, V. 2005. Ukrainian mythology. Kiev: Lybid'. Ukraine.

Yakimova, S. 2014. Symbol of the color in Spanish and Ukrainian artistic texts. Odessa linguistic herald. No 3. Odessa. Ukraine.

Zhaivoronok, V. 2006. Signs of Ukrainian Ethnoculture: Dictionary-Directory. Kiev: Dovira. Ukraine.

Zhampeisov, K., Balykbayev, T., Kolumbayeva, N. K. S., \& Aitpayeva, A. (2018). National Component of the Training Content of the Teachers in Kazakhstan's school. Opción, 34(85-2), 653-677. 